Ficus repens, a more marked response was obtained. Cuttings planted on April 22 and examined after 19 days showed in the control set 10 per cent rooted with an average of 0.3 roots per cutting and an average length of root per cutting of $1.6 \mathrm{~mm}$. Of cuttings treated for 3 hours with a skatole solution of a concentration of $20 \mathrm{mgm}$. per 100 c.c., 90 per cent were rooted with an average of 4.2 roots per cutting and an average length of root per cutting of $38 \cdot 4 \mathrm{~mm}$.

Parallel experiments showed $l$-tryptophane to be inactive.

Botany Department,

L. G. G. WARNE.

A. A. JACKSON.

Victoria University of Manchester.

$$
\text { June } 1 .
$$

1 NATURE, 137, 320 (1936).

${ }^{2}$ Contrib. Boyce Thompson Inst., 8, 63 (F936).

\section{Function of the Gills of the Mayfly Nymph, Cloeon dipterum}

IT is generally supposed that the plate-like abdominal gills occurring in some ephemerid nymphs are respiratory organs, although little experimental evidence is available to support this view. More. over, both Dewitz ${ }^{1}$ and Cuénot ${ }^{2}$ have shown that these gills are not essential to life. Recently, another function has been ascribed to these structures by Eastham ${ }^{3}$, who shows that in the nymph of the may. fly, Ecdyonurus venosus, they act as peddles which bathe with water the gill tufts attached to their bases.

In order to test whether or not the gill plates are truly respiratory in nature, the oxygen consumption of both the normal and gill-less nymphs of the mayfly, Cloeon dipterum, has been measured at $10^{\circ} \mathrm{C}$. at various oxygen concentrations. The results are shown in Fig. 1, each point in which is the average of three to eight experiments. This figure may be compared with Fig. 1 of Fox, Wingfield and Simmonds 4 .

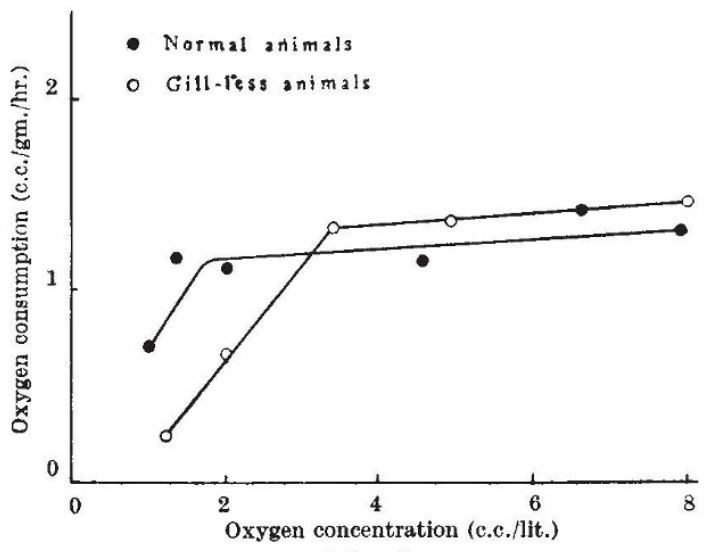

Fig. 1.

It will be seen that, as the oxygen content of the water is decreased, the oxygen consumption of both the normal and the gill-less nymphs remains nearly the same until a concentration of about 3 c.c./lit. is reached. Below this concentration the oxygen consumption of the gill-less nymphs falls off rapidly, but this marked decrease does not occur in the normal animals until the oxygen content of the water is reduced to about 1.5 c.c./lit. It is clear that the gills in this species of mayfly nymph only aid the oxygen consumption in water of low oxygen concentration, that is, below 3 c.c./lit.

At high oxygen concentrations, the gills of Cloeon dipterum only beat intermittently, but as the oxygen content of the water falls the quiescent periods are much reduced, thus causing a greater volume of water to pass over the dorsal surface of the animal in a given time.

It is not yet clear whether at low oxygen concentrations the level of oxygen consumption in the normal animal is maintained by gaseous exchange taking place at the gill surface, or whether under these conditions the gills merely act as paddles which pass a greater volume of water over the respiratory surfaces of the animal. Either of these processes would enable the animal to maintain its normal level of oxygen consumption at low oxygen concentrations.

The results summarized above will be published in full elsewhere.

Zoology Department,

University of Birmingham. May 14.

? Dewitz, H., Zool. Anz., 13, 525 (1890).

2 Cuénot, L., "L'Adaptation", Paris (1925).

${ }^{3}$ Eastham, L., J. Exp. Biol., 14, 219 (1937).

' Fox, H. Munro, Wingfield, C. A., and Simmonds, B. G., J. Exp. Biol., 14, 210 (1936).

\section{Zoological Nomenclature}

In spite of various criticisms, it must be admitted that the system of nomenclature used by zoologists and botanists is fundamentally sound and serviceable. Much depends, however, upon uniformity of practice, and certain irregularities which are becoming current are likely to cause serious confusion.

The International Code, Article 10, states : "When it is desired to cite the name of a subgenus, this name is to be placed in parenthesis between the generic and the specific names. Example: Vanessa (Pyrameis) cardui." The example is not well chosen, Pyrameis being a synonym of Vanessa; but the meaning is clear.

In the admirable Review of Applied Entomology, it has become the custom to cite an alternative generic name as if (according to the above rule) it were a subgenus. Thus, in the part for February 1937 we read. "Aonidiella (Chrysomphalus) aurantii", for the red scale of the orange. Chrysomphalus is the older name, and opinions differ as to whether the red scale should be referred to that genus, with Aonidiella as a subgenus, or whether Aonidiella should be raised to full generic rank. The method of citation used by the Imperial Institute of Entomology, and indeed by others, would be intelligible were it not for the instructions given (following the usage of many decades) in article 10 . If the method proposed in article 10 is abandoned, it is difficult to see how subgenera can be properly cited.

A quite different tendency, which seems to be on the increase, is to cite subgenera as if they were genera. An example (many more might be found) is furnished by C. Frick's "Horned Ruminants of North America", just published. A new subgenus Stockoceros is proposed for Tetrameryx conklingi of Stock ; but although 